\title{
PREFACE
}

\section{Low Impact Development and Sponge City Construction for Urban Stormwater Management}

\author{
Selected Papers from the 2016 International Low Impact Development \\ Conference in Beijing, China
}

\author{
Haifeng Jia (凶) ${ }^{1}$, Shaw L. Yu ${ }^{2}$, Huapeng Qin ${ }^{3}$ \\ 1 School of Environment, Tsinghua University, Beijing 100084, China \\ 2 Department of Civil \& Environmental Engineering, University of Virginia, Charlottesville, VA 22903, USA \\ 3 School of Environment and Energy, Shenzhen Graduate School of Peking University, Shenzhen 518055, China
}

(C) Higher Education Press and Springer-Verlag Berlin Heidelberg 2017

Low Impact Development and Sponge City Construction are new paradigm for Urban Stormwater Management. It has become a hot focus in urban water resources research and practices globally. In this context, in order to provide an international forum for stormwater management professionals to present the latest developments, technologies and case studies related to low impact development (LID) and green infrastructure (GI) technology, the 2016 International Low Impact Development Conference was organized and held. The Conference was jointly sponsored by the Water Industrial Society of the Chinese Society of Civil Engineers, the Water Environment Research Institute of the American Society of Civil Engineers and the Chinese Academy of Engineering. Organizers included Tsinghua University, Peking University and Beijing University of Civil Engineering and Architecture.

The conference was the very first major gathering of LID/GI professionals in China. It was a timely event, as China had just initiated a monumental effort in sustainable urban development. The Sponge City Construction Plan, released in 2014, announced a new paradigm that calls for the use of natural systems such as soiland vegetation as part of the urban runoff control strategy.The principles of the Sponge City approach are similar to those of the LID/GI technology. Recognizing the limitation of LID/GI facilities in controlling large or less frequentstorm events, the government mandates the integration of green and gray infrastructure. During 2015 and 2016, the Chinese government selected 30 cities as pilot sites under the Sponge City Plan. Each city is to receive 400 to 600 million RMB ( $\$ 60-90$ million) annually for three years, with the total investment estimated to be about 42.3 billion RMB, or $\$ 6.4$ billion. The nationwide implementation of Preface construction will involve an enormous scale of LID/GI facility planning, construction, etc. The Conference provided a platform for sharing experiences and research findings among practitioners from all over the world. Such information and lessons-learned would be useful references for China's Sponge City projects.

The 2016 International Low Impact Development Conference drew a great deal of interest nationally and internationally. More than 1,200 delegates from over 20 countries attended the meeting. There were 9 keynote speeches, 6 tracks of regular sessions and 11 special sessions organized by experts in various subjects. Subjects covered ranged from theory to practice of LID/GI practices, such as bioretention design, green roof modeling, stormwater regulations, technical guidance, etc. In addition, 6 pre-conference workshops were given and several post-conference forums were held in Shenzhen, Pingxiang, et al. Also at the conference, a declaration, "The Beijing Consensus: Low Impact Development for Urban Stormwater Management", was presented. The declaration represents the general consensus of delegates regarding

Received July 15, 2017

Corresponding author

E-mail: jhf@tsinghua.edu.cn

Hot Column—Low Impact Development and Sponge City (Guest Editors: Haifeng Jia \& Shaw L. Yu) 
the strategy for urban stormwater management moving forward.

We have selected 16 papers from the over 200 full papers submitted to the Conference for publication as a special issue in FESE. These papers cover a wide spectrum of subjects on LID/GI research and applications. The feature article propose a concept of urban water system 3.0 and discuss the approach on upgrading to urban water system 3.0 through Sponge City Construction. There are papers dealing with basic research on bioretention efficiency impacted by plants, media and other parameters. Several papers discussed modeling of LID practices such as green roof, permeable pavement, etc. for optimal design and operation. One paper presented a comprehensive, state-of-art review of the LID/GI technology. A recount of the historical development of the sustainable urban drainage design strategy in Australia is included, so is a paper reporting LID practice performance in cold climates such as Canada. There is a comprehensive review paper on the Sponge City Construction projects in China, and a paper discussing some important technical approaches recommended for the implementation of Sponge City projects.

In summary, the 2016 Low Impact Development Conference has helped highlight the monumental and visionary efforts China has been making since 2014 in promoting a sustainable urbanization strategy that has attracted international attention and recognition. The success of the Sponge City Construction projects will go a long way in providing valuable data and information for LID/GI professionals all over the world.

We acknowledge the sponsorship and financial support provided for the conference. Efforts by all the authors, editors and assistance by the Editorial Office of FESE are greatly appreciated. In particular, we appreciate the support from Professor Xia Huang, Executive Assocaite Editor-in-Chief of FESE, for agreeing to dedicate an issue to this conference. Also, we are grateful to Ms. Xiangyi Zhang, and Mr. Lizheng Wang in the editor's office for their kind help. We also wish to thank the reviewers. Their precious time and invaluable and detailed suggestions have been especially helpful in improving the quality of each paper and, therefore, this special issue. 